\title{
VULNERABILIDADE NATURAL DOS SOLOS E ÁGUAS DO ESTADO DE GOIÁS À CONTAMINAÇÃO POR VINHAÇA UTILIZADA NA FERTIRRIGAÇÃO DA CULTURA DE CANA-DE-AÇÚCAR
}

\author{
VULNERABILITY OF SOILS AND NATURAL WATERS OF THE STATE \\ OF GOIÁS TO THE CONTAMINATION BY VINASSE USED \\ IN FERTIGATION OF SUGAR CANE CULTURE
}

\author{
VULNERABILIDAD DE LOS SUELOS Y AGUAS NATURALES \\ DEL ESTADO DE GOIÁS A LA CONTAMINACIÓN POR VINAZA \\ UTILIZADA EN EL FERTIRRIEGO DE CULTURA DE CAÑA DE AZÚCAR
}

\author{
Maria Gonçalves da Silva Barbalho - Universidade Federal de Goiás - Goiânia - Goiás - Brasil \\ maria-gsb@sefaz.go.gov.br
}

Alfredo Borges De-Campos - Universidade Federal de Goiás - Goiânia - Goiás - Brasil

alfredo_de_campos@yahoo.com

\section{Resumo}

A cultura da cana-de-açúcar tem se expandido no estado de Goiás, implicando em um reordenamento do uso do solo com possíveis consequências ambientais. 0 presente trabalho teve como objetivo avaliar a vulnerabilidade natural dos solos e águas superficiais e subterrâneas do estado de Goiás à contaminação por vinhaça, que é o principal subproduto decorrente do processamento da cana-de-açúcar para produção de álcool combustível (etanol). A vinhaça é frequentemente utilizada como fertilizante nos solos e, por isso, pode constituir um poluente quando aplicada indevidamente. A metodologia empregada consistiu na avaliação da vulnerabilidade natural das terras à contaminação por vinhaça mediante análise integrada dos seguintes parâmetros: declividade, tipos e condutividade hidráulica dos solos. A partir da análise desses parâmetros, as classes de vulnerabilidade natural dos solos foram determinadas e correlacionadas com a distribuição espacial das usinas de álcool, objetivando definir cenários potenciais de contaminação dos solos e águas por constituintes químicos da vinhaça. $0 \mathrm{~s}$ resultados revelaram que áreas com "muito alta" e "alta" vulnerabilidade abrangem cerca de $57 \%$ das terras do estado que podem ser ocupadas pela cana-de-açúcar, o que define um futuro cenário ambiental preocupante no que concerne à qualidade e gestão de solos e águas.

Palavras-chave: vulnerabilidade, solo, água, cana-de-açúcar, vinhaça, contaminação.

\section{Abstract}

Sugar cane production has increased in the State of Goias, Central Brazil. This growth may imply environmental concerns because sugar cane processing will generate large amounts of vinasse, a nutrient-rich liquid waste that is often used to improve soil fertility. However, vinasse may be a contaminant when applied to soils as a fertilizer. The objective of this paper was to evaluate the natural vulnerability of soils and surface and subsurface waters to chemical contamination by vinasse. To carry out the research, an integrated spatial analysis of slope steepness, soil type and hidraulical conductivity was performed to determine the degree of vulnerability of lands (soil and water) to be contaminated by vinasse. Four degrees of land vulnerability were chosen (very high, high, medium, low) and those correlated with sugar cane processing plants to define potential contamination scenarios. The results showed that areas with very high and high vulnerability was about $57 \%$, which indicates the lands of the State of Goiás are highly vulnerable to pollution by vinasse, if the waste is not properly managed. Key words: vulnerability, soil, water, sugar cane, vinasse, contamination. 


\section{Resumen}

La producción de azúcar de caña ha aumentado en el Estado de Goias, Brasil Central. Este crecimiento puede implicar problemas medioambientales ya que el procesamiento de caña de azúcar va a generar grandes cantidades de vinaza, un residuo líquido rico en nutrientes que se utiliza a menudo para mejorar la fertilidad del suelo. Sin embargo, la vinaza puede ser un contaminante cuando se aplica a los suelos como fertilizante. El objetivo de este trabajo fue evaluar la vulnerabilidad natural de los suelos y las aguas superficiales y subterráneas a la contaminación química de la vinaza. Para llevar a cabo la investigación, se realizó un análisis espacial integrado de inclinación de la pendiente, tipo de suelo y la conductividad hidráulica para determinar el grado de vulnerabilidad de las tierras (suelo y agua) que se contaminan con vinaza. Cuatro grados de vulnerabilidad de la tierra fueron elegidos (muy alto, alto, medio, bajo) y correlacionados con las plantas de transformación de azúcar de caña para definir los escenarios potenciales de contaminación. Los resultados mostraron que las zonas con vulnerabilidad muy alta y alta fueran en torno al $57 \%$, lo que indica las tierras del Estado de Goiás son altamente vulnerables a la contaminación por vinazas, si los residuos no se gestionan adecuadamente. Palabras clave: vulnerabilidad, suelo, água, azúcar de caña, decantación, la contaminación.

\section{Introdução}

Estamos presenciando uma mudança no cenário da produção agrícola do estado de Goiás determinado pela expansão da cultura da cana-de-açúcar. Isto se deve ao reaquecimento da produção de álcool combustível (etanol) no mercado interno, em razão da produção de carros bicombustíveis (flex), e, no mercado internacional, ao aumento dos preços do petróleo e busca por fontes energéticas renováveis.

Na safra 2006/2007 o Brasil produziu cerca de três bilhões de litros de álcool (Jornal da Cana, 2007, p. 3), sendo que, para cada litro de álcool produzido, são gerados de 10 a 18 litros de vinhaça (Rossetto, 1987, p. 436). Pelo volume de álcool e vinhaça produzidos, fica claro que a gestão adequada da vinhaça é fundamental para que não se comprometam os solos e recursos hídricos nas áreas onde estes efluentes são dispostos e/ou utilizados como fertilizantes.

A monocultura de cana-de-açúcar é uma das atividades agrícolas mais preocupantes no que se refere à contaminação dos solos e das águas subterrâneas por causa da utilização de vinhaça como fertilizante durante o cultivo da planta. A vinhaça apresenta alto valor fertilizante em razão da sua riqueza em potássio, matéria orgânica e teor de água. Por esse motivo, passou a ser aplicada nas lavouras de cana-de-açúcar, uma vez que pode promover a adição de nutrientes ao solo, elevar a umidade, o teor de matéria orgânica e o pH, além de melhorar a resistência do solo à erosão, resultando no aumento da produtividade agrícola (Cambuim, 1983, p. 133). Entretanto, a vinhaça caracteriza-se como um efluente de 
destilarias com alto poder poluente decorrente da sua riqueza em matéria orgânica, baixo $\mathrm{pH}$, elevada corrosividade e alta demanda bioquímica de oxigênio (DBO), além da sua elevada temperatura na saída dos destiladores, o que faz com que seja considerada nociva à fauna e à flora (Freire e Cortez, 2000, p. 23).

Estudos anteriores apontam que quando a vinhaça é aplicada no solo mediante a fertirrigação, uma parcela significativa dos íons existentes na vinhaça, tais como nitrato e potássio, podem percolar através do solo e atingir o lençol freático por meio de processos de lixiviação (Silva et al., 2007, p. 109; Ludovice, 1996, p. 5-6). No estudo desenvolvido por Silva (2007) em solos de cerrado foi demonstrado que a vinhaça promove a alcalinização do solo e que doses iguais ou superiores a $1200 \mathrm{~m}^{3} \mathrm{ha}^{-1}$ favorecem o aumento da concentração de potássio no efluente e a formação de complexos de $\mathrm{Ca}^{2+}$ e $\mathrm{Mg}^{2+}$ com ânions de $\mathrm{SO}_{4}{ }^{2-}$, $\mathrm{Cl}^{-}$e matéria orgânica, o que facilita a dispersão e a lixiviação dos solos.

O poder poluente da vinhaça nos solos depende das características destes. Ludovice (1996, p. 6) observou que solos com alto teor de argila tendem a reduzir a demanda química de oxigênio (DBO) produzida pela vinhaça e, em consequência, podem diminuir os impactos da vinhaça sobre as águas percolantes nos solos. Desta forma, características dos solos como tipo, posicionamento topográfico e capacidade de infiltração devem ser consideradas para fins de avaliação do potencial poluidor da vinhaça nos solos e águas, bem como para indicar a vulnerabilidade natural das terras a este tipo de poluente. Entretanto, poucos são os estudos que avaliam o potencial poluidor da vinhaça sobre o solo e as águas subterrâneas (Lyra et al., 2003, p. 525).

A expansão da monocultura de cana-de-açúcar no estado de Goiás pode levar à ocupação de novas áreas com a consequente destruição de habitats e impactos sobre a biodiversidade, bem como à degradação do solo (erosão e contaminação), à poluição dos recursos hídricos superficiais e subsuperficiais e à redução da disponibilidade hídrica decorrente da captação de água de áreas já ocupadas para fins agrícolas. Vale ressaltar que, nas últimas safras, o estado de Goiás tem despontado como área de expansão notável do cultivo de cana-de-açúcar com um aumento de 81\% da área plantada entre as safras de 1999-2000 e 2003-2004, o que corresponde a um acréscimo de 6,6\% da produção canavieira em nível nacional (IEL, 2006). 
Em face da perspectiva de expansão da cultura da cana-de-açúcar e da diversidade do meio físico do estado de Goiás, é necessário adquirir um conhecimento detalhado do grau de vulnerabilidade dos solos e águas do estado à contaminação por vinhaça utilizada na fertirrigação. Ressalte-se que a identificação de graus de vulnerabilidade natural das terras (Foster et al., 2003, p. 2) pode constituir um importante instrumento de planejamento do uso das terras e de controle ambiental.

Objetivou esta pesquisa estimar a vulnerabilidade natural das terras (solos e recursos hídricos superficiais e subsuperficiais) do estado de Goiás à contaminação por vinhaça. Para avaliar a vulnerabilidade natural das terras foram consideradas a declividade do relevo, os tipos de solos e a condutividade hidráulica destes.

\section{Área de estudo}

O estado de Goiás localiza-se na região Centro-Oeste do país e tem uma área de $350.613 \mathrm{~km}^{2}$. Apresenta um relevo de suave a ondulado na maior parte de seu território, que é caracterizado por extensas chapadas onde se localizam nascentes das bacias hidrográficas dos rios Paraná, São Francisco e Tocantins-Araguaia. A esse tipo de relevo se associam em geral solos da classe dos Latossolos, que são solos profundos, porosos e bem drenados, e que são em geral bastante suscetíveis a processos de lixiviação (Carvalho e Podestá Filho, 1989, p. 91-105), com consequente transporte de poluentes. O clima é do tipo tropical sub-úmido, quente, com duas estações bem marcadas: inverno seco (maio a setembro) e verão chuvoso (outubro a abril), quando ocorre a maioria das precipitações pluviométricas (De Campos et al., 2001, p. 91-118). Em virtude do extenso período de estiagem durante o inverno, pode haver grande pressão sobre os recursos hídricos para fins de irrigação. E se esta for acompanhada da fertirrigação por vinhaça, poderá ocorrer contaminação dos solos e das águas superficiais e subterrâneas.

\section{Metodologia}

A metodologia utilizada para a realização desta pesquisa foi baseada em Gomes, Spadotto e Pessoa (2002, p. 170), que propuseram um método de avaliação da vulnerabilidade natural dos solos como forma de 
subsidiar estudos relativos à movimentação de agroquímicos, principalmente aqueles preocupados com a avaliação de riscos de contaminação das águas subterrâneas. Com este fim, foram considerados os seguintes parâmetros: declividade, tipos e condutividade hidráulica dos solos.

Para o presente estudo foram utilizados mapa de solos do estado de Goiás na escala 1:1.000.000 e dados sobre condutividade hidráulica destes, obtidos a partir da distribuição estatística de resultados de infiltração in situ conduzidos nas diferentes classes de solos em superfície e em profundidade (Almeida et al., 2006, p. 129-135). A partir dos dados pontuais de condutividade hidráulica dos solos e do mapa de solos do estado de Goiás, foi gerada uma classificação quanto à condutividade hidráulica dos solos para fins de espacialização, apresentando as seguintes classes: muito alta, alta, moderada e baixa (Quadro 1).

Quadro 1 - Classes de condutividade hidráulica dos solos

\begin{tabular}{|c|c|}
\hline $\begin{array}{c}\text { Classes de Condutividade Hidráulica } \\
\text { (Valores em kV - Ordem de Grandeza em m/s) }\end{array}$ & Classes ou Associações de Solo \\
\hline Muito Alta - $>10^{-3}$ & Neossolos Quartzarênicos \\
\hline Alta $-10^{-3}$ a $10^{-5}$ & Latossolos \\
\hline Moderada $-10^{-6}$ & Argissolos, Nitossolos \\
\hline Baixa $-10^{-7}$ a $10^{-8}$ & $\begin{array}{c}\text { Cambissolos, Plintossolos, Neossolos } \\
\text { Litólicos, e Gleissolos. }\end{array}$ \\
\hline
\end{tabular}

Utilizando-se curvas de nível e pontos cotados, foi gerado o mapa de declividade no programa Spring a partir de uma grade triangular ou TIN. Posteriormente, foi realizado o fatiamento da grade, correspondendo as fatias às classes de declividades definidas nos seguintes intervalos: Baixa - de 0-6\%, correspondendo às áreas planas ou quase planas que apresentam declives suaves onde o escoamento superficial é lento; Suave - de 6-12\%, compreendendo áreas com relevo ondulado e escoamento superficial médio ou rápido (dependendo do tipo de solo); Moderada - de 12-18\%, são áreas inclinadas que apresentam um escoamento superficial rápido; Acentuada - 18-45\%, com vertentes fortemente inclinadas, cujo escoamento é muito rápido.

Tomando como base as classes de condutividade hidráulica dos solos (Quadro 1) e de declividade foi estabelecida a relação matricial que resultou na classificação do potencial de infiltração e escoamento super- 
ficial das águas no solo (Quadros 2 e 3). A metodologia utilizada nessa fase foi uma adaptação daquela que foi proposta por Gomes et al. (1996a).

Quadro 2 - Potencial de infiltração em relação à declividade e à condutividade hidráulica

\begin{tabular}{|c|c|c|c|c|}
\hline \multirow{2}{*}{ Condutividade } & \multicolumn{4}{|c|}{ Declividade } \\
\cline { 2 - 5 } & Baixa & $\begin{array}{c}\text { Suave } \\
6-2 \%\end{array}$ & $\begin{array}{c}\text { Moderada } \\
12-18 \%\end{array}$ & $\begin{array}{c}\text { Alta } \\
\end{array}$ \\
\cline { 2 - 5 } & Médio & Baixo & Baixo & Baixo \\
\hline Baixa & Alto & Médio & Baixo & Baixo \\
\hline Media & Alto & Alto & Médio & Baixo \\
\hline Alta & Alto & Alto & Alto & Médio \\
\hline Muito Alta & &
\end{tabular}

Quadro 3 - Potencial de escoamento superficial em relação à declividade e a condutividade hidráulica

\begin{tabular}{|c|c|c|c|c|}
\hline \multirow{2}{*}{ Condutividade } & \multicolumn{4}{|c|}{ Declividade } \\
\cline { 2 - 5 } & $\begin{array}{c}\text { Baixa } \\
0-6 \%\end{array}$ & $\begin{array}{c}\text { Suave } \\
6-12 \%\end{array}$ & $\begin{array}{c}\text { Moderada } \\
12-18 \%\end{array}$ & $\begin{array}{c}\text { Alta } \\
18-45 \%\end{array}$ \\
\hline Baixa & Médio & Alto & Alto & Alto \\
\hline Moderada & Baixo & Médio & Alto & Alto \\
\hline Alta & Baixo & Baixo & Médio & Alto \\
\hline Muito Alta & Baixo & Baixo & Baixa & Médio \\
\hline
\end{tabular}

O potencial de infiltração classificado como "alto" e "muito alto" (em decorrência da condutividade hidráulica e da baixa declividade) indica alta vulnerabilidade das terras à contaminação das águas subterrâneas, com possibilidade de chegada do produto contaminante até os corpos d'água mais profundos. Já o potencial de escoamento classificado como "muito alto" e "alto" indica que as terras são mais vulneráveis à erosão e à contaminação dos corpos d'água superficiais.

Posteriormente, foi realizada a classificação da vulnerabilidade das terras à contaminação por vinhaça em razão da integração das informações de condutividade hidráulica dos solos, declividade do terreno, potenciais de infiltração e de escoamento superficial da água (Quadro 4), com uso da ferramenta Legal do programa Spring. As classes de vulnerabilidade das terras estabelecidas foram as seguintes: "muito alta", "alta", "moderada", "baixa". 
Quadro 4 - Classificação da vulnerabilidade das terras à contaminação por vinhaça

\begin{tabular}{|c|c|c|c|c|}
\hline $\begin{array}{c}\text { Declividade } \\
\text { do Terreno }\end{array}$ & Condutividade & $\begin{array}{c}\text { Potencial de } \\
\text { Infiltração da } \\
\text { Água }\end{array}$ & $\begin{array}{c}\text { Potencial de } \\
\text { Escoamento da } \\
\text { Água }\end{array}$ & $\begin{array}{c}\text { Vulnerabilidade das } \\
\text { Terras }\end{array}$ \\
\hline Baixa & Muito Alta & Alto & Baixo & Muito Alta \\
\hline Baixa & Alta & Alto & Baixo & Alta \\
\hline Baixa & Média & Alto & Médio & Moderada \\
\hline Baixa & Baixa & Médio & Baixo & Baixa \\
\hline Suave & Muito Alta & Alto & Baixo & Muito Alta \\
\hline Suave & Alta & Alto & Baixo & Alta \\
\hline Suave & Média & Médio & Médio & Moderada \\
\hline Suave & Baixa & Baixo & Baixo & Baixa \\
\hline Moderada & Muito Alta & Alta & Baixo & Muito Alta \\
\hline Moderada & Alta & Médio & Médio & Alta \\
\hline Moderada & Moderada & Baixo & Médio & Moderada \\
\hline Moderada & Baixa & Baixo & Baixo & Baixa \\
\hline Alta & Muito Alta & Médio & Médio & Moderada \\
\hline Alta & Alta & Baixo & Médio & Moderada \\
\hline Alta & Moderada & Baixo & Alto & Baixa \\
\hline Alta & Baixa & Baixo & Alto & Baixa \\
\hline
\end{tabular}

Nos mapas apresentados foram acrescentadas as localizações das usinas de álcool do estado de Goiás que se encontram nas fases de implantação, projeto, análise e em operação no ano de 2007, que já utilizam ou devem vir a utilizar fertirrigação com vinhaça. Os dados das usinas foram compilados de Castro et al. (2007, p. 12).

\section{Resultados}

No estado de Goiás há o predomínio da classe Latossolo Vermelho, seguido de outras classes como o Latossolo Vermelho-Amarelo, Cambissolo, Argissolo e Neossolo (Figura 1; Tabela 1). Os Latossolos são as classes predominantes (45\%) e se concentram principalmente na porção centro-sul do estado sobre áreas drenadas pela bacia hidrográfica do rio Paraná. Observa-se que todas as usinas de álcool projetadas, em implantação ou em funcionamento em Goiás no ano de 2007 estão sobre áreas de Latossolos (Tabela 1). 
Figura 1 - Mapa de solos do estado de Goiás

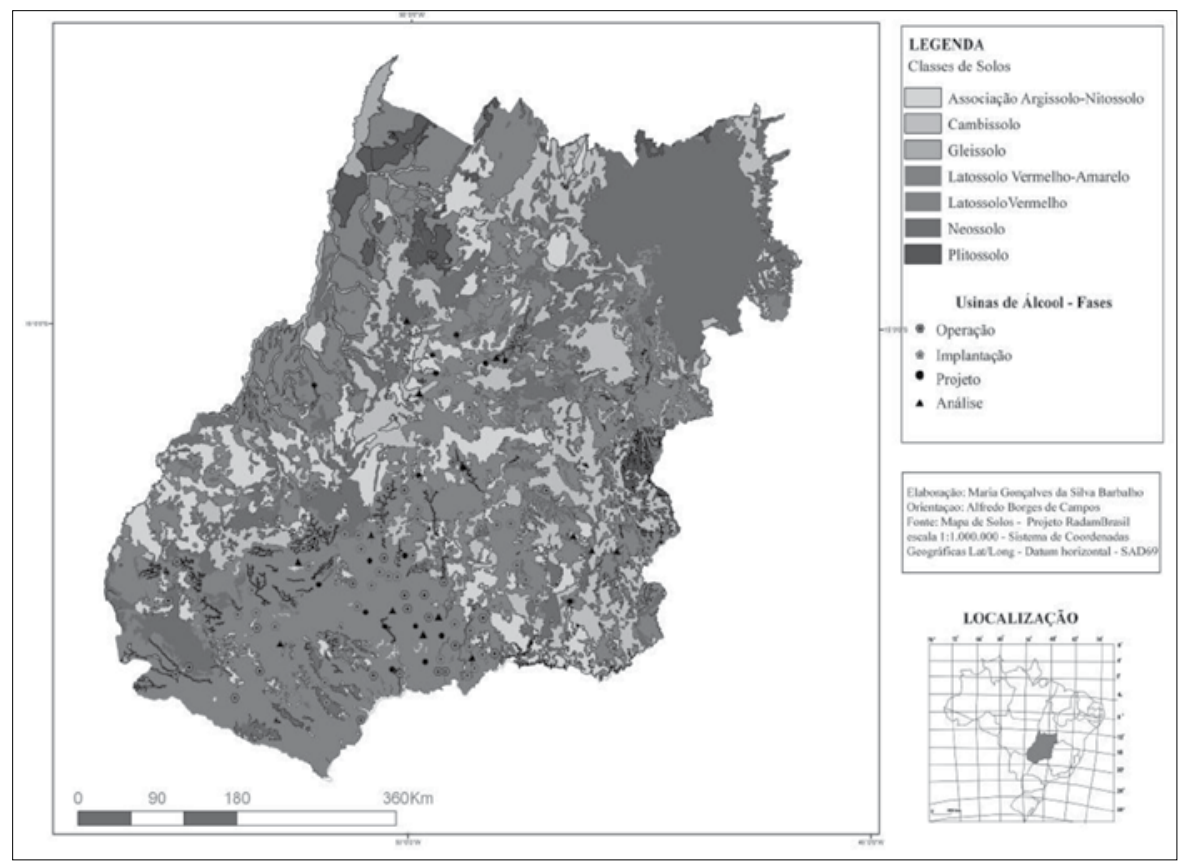

Fonte: Agência Ambiental - Base de dados - Determinação de áreas prioritárias para unidades de preservação.

Tabela 1 - Distribuição das classes de solo e das usinas de álcool em Goiás

\begin{tabular}{l|c|c|c|c|c|c|c}
\hline \multirow{2}{*}{$\begin{array}{l}\text { Classes } \\
\text { de Solos }\end{array}$} & \multirow{2}{*}{$\begin{array}{c}\text { Área } \\
\text { (ha) }\end{array}$} & \multirow{2}{*}{$\begin{array}{c}\text { Área } \\
(\%)\end{array}$} & \multicolumn{5}{|c}{ Usinas de Álcool } \\
\cline { 5 - 8 } & & Operação & Implantação & Projeto & Análise & Total \\
\hline $\begin{array}{l}\text { Neossolo } \\
\text { Litólico }\end{array}$ & 3.890 .900 & 11,26 & - & - & - & - & - \\
\hline $\begin{array}{l}\text { Neossolo } \\
\text { Quartzarênico }\end{array}$ & 1.242 .800 & 3,60 & - & - & - & - & - \\
\hline $\begin{array}{l}\text { Associação } \\
\text { Argissolo- }\end{array}$ & 4.896 .700 & 14,17 & - & - & - & - & - \\
Nitossolo & 1.320 .000 & 3,82 & - & - & - & - & - \\
\hline Plintossolo & 6.213 .400 & 17,98 & - & - & - & - & - \\
\hline Cambissolo & & & & & & & (continua)
\end{tabular}




\begin{tabular}{|c|c|c|c|c|c|c|c|}
\hline \multirow{2}{*}{$\begin{array}{l}\text { Classes } \\
\text { de Solos }\end{array}$} & \multirow{2}{*}{$\begin{array}{l}\text { Área } \\
\text { (ha) }\end{array}$} & \multirow{2}{*}{$\begin{array}{c}\text { Área } \\
(\%)\end{array}$} & \multicolumn{5}{|c|}{ Usinas de Álcool } \\
\hline & & & Operação & Implantação & Projeto & Análise & Total \\
\hline $\begin{array}{l}\text { Latossolo } \\
\text { Vermelho }\end{array}$ & 10.398 .600 & 30,09 & 22 & 21 & 30 & 15 & - \\
\hline $\begin{array}{l}\text { Latossolo } \\
\text { Vermelho- } \\
\text { Amarelo }\end{array}$ & 5.246 .800 & 15,18 & 3 & 2 & 3 & 4 & - \\
\hline Gleissolo & 1.242 .800 & 3,60 & - & - & - & - & - \\
\hline Água & 104.600 & 0,30 & - & - & - & - & - \\
\hline Total & 34.556 .600 & 100 & 25 & 23 & 33 & 19 & 100 \\
\hline
\end{tabular}

Os dados de declividades permitiram constatar que grande parte das terras do estado de Goiás possui declives baixos (declividade $<12 \%$ ), principalmente aqueles terrenos posicionados sobre áreas planas (chapadas) localizadas nas porções centro-sul, sudoeste-sudeste e noroeste do estado (Figura 2; Tabela 2).

Figura 2 - Mapa de declividade do Estado de Goiás

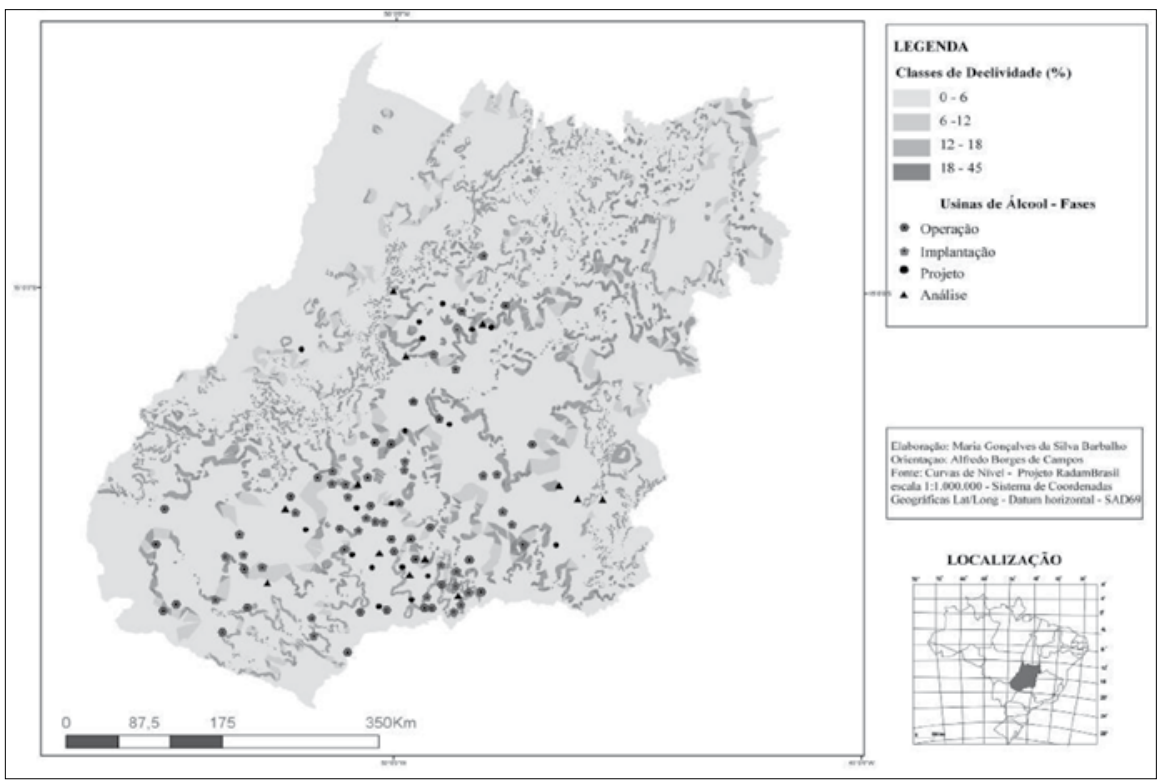


Tabela 2 - Distribuição das classes de declividade no estado de Goiás

\begin{tabular}{l|c|c}
\hline \multirow{2}{*}{ Classes de Declividade } & \multicolumn{2}{|c}{ Área } \\
\cline { 2 - 3 } & (ha) & (\%) \\
\hline $0-6-$ Baixa & $27.188 .791,04$ & 78,68 \\
\hline $6-12-$ Suave & $4.343 .715,56$ & 12,57 \\
\hline $12-18-$ Moderada & $1.919 .882,32$ & 5,56 \\
\hline $18-45-$ Acentuada & $1.104 .283,12$ & 3,20 \\
\hline Total & $34.556 .672,04$ & 100 \\
\hline
\end{tabular}

Solos com alta condutividade hidráulica são comuns em Goiás (Figura 3; Tabela 3). Eles aparecem na porção centro-sul do estado, tendo ocorrência substancial na região sudoeste em áreas pertencentes à bacia hidrográfica do rio Paraná. Os solos com baixa condutividade são menos representativos e abrangem áreas da bacia hidrográfica dos rios Tocantins e Araguaia. A grande maioria das usinas de álcool encontra-se localizada sobre áreas com alta infiltração.

Tabela 3 - Distribuição das classes de condutividade hidráulica dos solos no Estado de Goiás

\begin{tabular}{l|r|r|c|c|c|c|c}
\hline \multirow{2}{*}{$\begin{array}{c}\text { Classes de } \\
\begin{array}{c}\text { Condutividade } \\
\text { Hidráulica } \\
\text { dos Solos }\end{array}\end{array}$} & $\begin{array}{c}\text { Área } \\
\text { (ha) }\end{array}$ & $\begin{array}{c}\text { Área } \\
(\%)\end{array}$ & & \multicolumn{5}{|c}{ Usinas de Álcool } \\
\cline { 6 - 9 } & $15.407 .549,76$ & 44,59 & 20 & 21 & 29 & 17 & 87 \\
\hline Alta & $1.226 .428,64$ & 3,55 & 1 & - & 3 & - & 4 \\
\hline Muito Alta & $4.446 .113,20$ & 12,87 & 4 & 1 & - & - & 5 \\
\hline Moderada & $13.417 .335,64$ & 38,83 & - & 1 & 1 & 2 & 4 \\
\hline Baixa & $59.244,80$ & 0,17 & - & - & - & - & - \\
\hline Drenagem & $34.556 .672,04$ & 100 & 25 & 23 & 33 & 19 & 100 \\
\hline Total & & & & & & & Implantação \\
\hline
\end{tabular}


Figura 3 - Mapa de condutividade hidráulica dos solos do Estado de Goiás

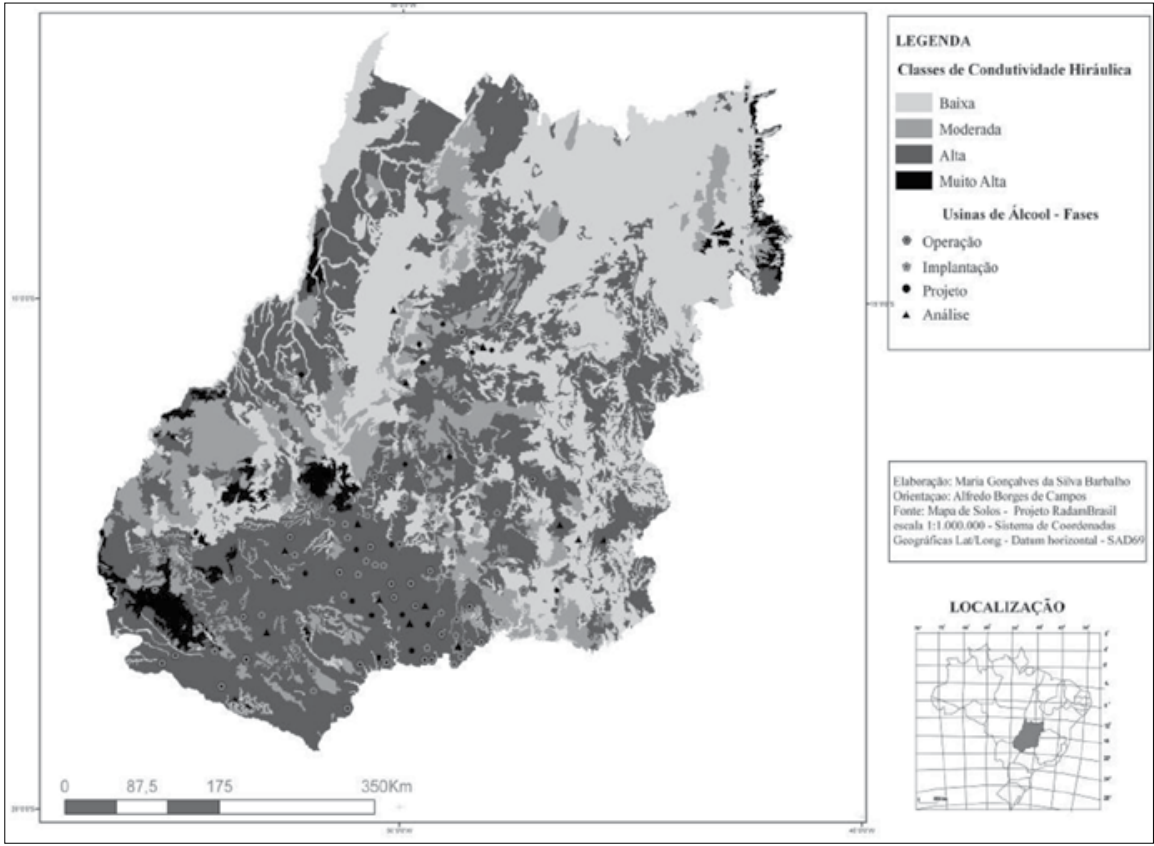

Terras que apresentam "muito alta" e "alta" vulnerabilidade à contaminação por compostos químicos decorrentes da fertirrigação por vinhaça são predominantes no estado de Goiás (Figura 4; Tabela 4). Estas perfazem cerca de $2 / 3$ da área total do estado e ocorrem principalmente na porção centro-sul, enquanto que as áreas classificadas com "moderada" a "muito baixa" vulnerabilidade à contaminação representam uma parcela bem menor da área total do estado e se concentram na região nordeste. Majoritariamente, as usinas de álcool estão localizadas sobre terras com alta vulnerabilidade à contaminação por vinhaça (Tabela 4). 
Figura 4 - Mapa de vulnerabilidade das terras à contaminação por vinhaça em Goiás

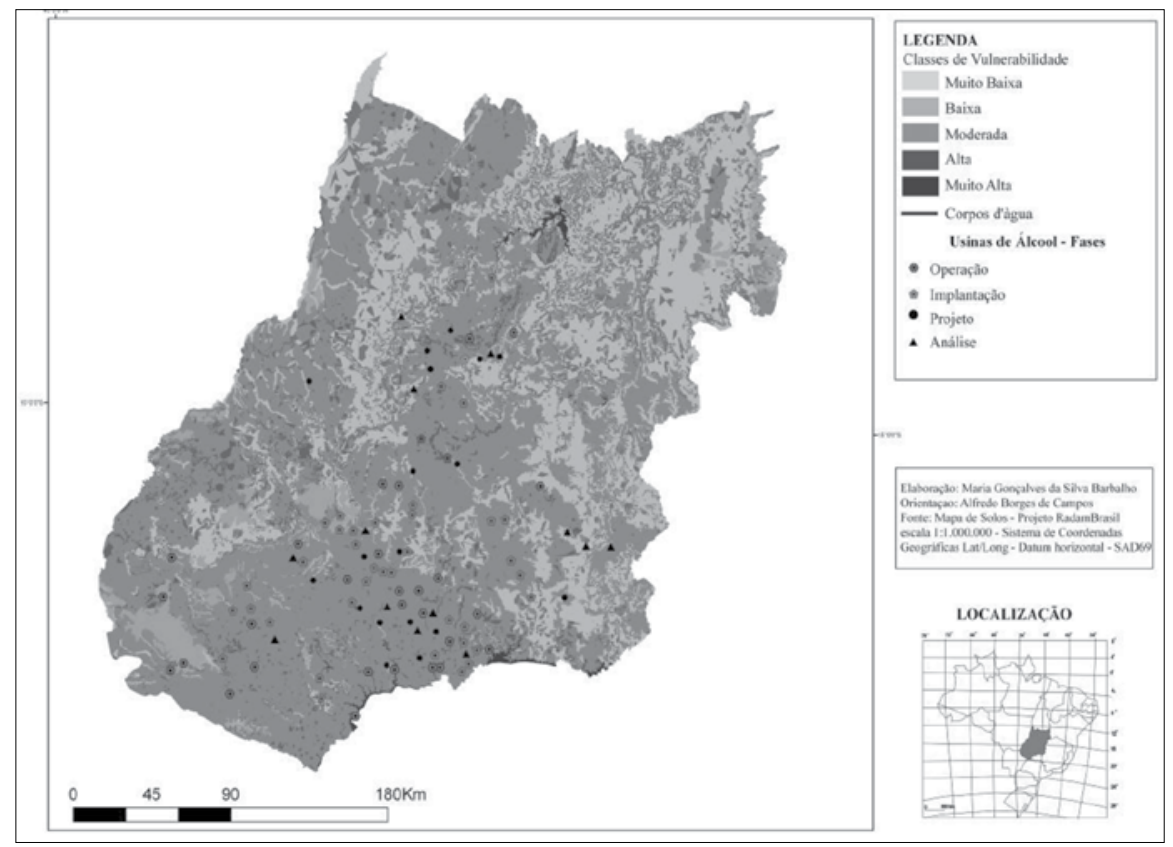

Tabela 4 - Dados estatísticos das classes de vulnerabilidade dos solos e águas à contaminação por vinhaça no estado de Goiás

\begin{tabular}{|c|c|c|c|c|c|c|c|}
\hline \multirow{2}{*}{$\begin{array}{l}\text { Classes de } \\
\text { Vulnerabilidade } \\
\text { à Contaminação } \\
\text { por Vinhaça }\end{array}$} & \multirow{2}{*}{$\begin{array}{l}\text { Área } \\
\text { (ha.) }\end{array}$} & \multirow{2}{*}{$\begin{array}{c}\text { Área } \\
(\%)\end{array}$} & \multicolumn{5}{|c|}{ Usinas de Álcool } \\
\hline & & & Operação & Implantação & Projeto & Análise & Total \\
\hline Muito Alta & $3.207 .122,82$ & 9,28 & 1 & - & 3 & - & 4 \\
\hline Alta & $19.767 .260,94$ & 57,21 & 20 & 21 & 29 & 17 & 87 \\
\hline Moderada & $10.107 .602,01$ & 29,25 & 4 & 1 & - & - & 5 \\
\hline Baixa & $1.269 .672,30$ & 3,67 & - & 1 & 1 & 2 & 4 \\
\hline Drenagem & $199.662,21$ & 0,58 & - & - & - & - & - \\
\hline Total & $34.551 .320,28$ & 100 & 25 & 23 & 33 & 19 & 100 \\
\hline
\end{tabular}




\section{Discussão}

A fertirrigação por vinhaça, especialmente em altas dosagens, pode introduzir nos solos elementos e compostos químicos solúveis em água e potencialmente poluentes como potássio e nitratos (Silva et al., 2007, p. 109). Esses compostos químicos, quando aplicados em solos bem drenados como os Latossolos, podem percolar através destes e atingir o lençol freático levando à contaminação das águas subterrâneas. No transporte desses compostos através dos solos, eles podem ser adsorvidos por constituintes da fração sólida ou serem lixiviados quando alcançam o limite de saturação do solo e, desta forma, atingem as águas superficiais. $\mathrm{O}$ risco potencial de contaminação do lençol freático e das águas superficiais depende, portanto, das quantidades de vinhaça aplicadas, da dinâmica hidrológica e das características químicas dos solos.

Como mostra a Figura 4, o estado de Goiás possui terras e águas altamente vulneráveis à contaminação por compostos químicos decorrentes da fertirrigação por vinhaça. A quase totalidade das usinas de álcool em operação, ou a serem implantadas no estado, localizam-se sobre zonas com alta vulnerabilidade à contaminação, onde predominam relevos com baixo declive e solos com alto gradiente hidráulico e, portanto, bem drenados e com alto poder lixiviante (Figuras 1, 2, 3 e 4).

Conforme pôde-se verificar nesta pesquisa, de acordo com Del'Arco e Bezerra (1989, p. 35-51), grande parte da área onde se encontram as usinas de álcool está localizada no setor centro-sul do estado sob substratos arenosos pertencentes à Bacia Sedimentar do Paraná, onde ocorrem áreas de recarga do aquífero Guarani. A concentração das usinas de álcool e das áreas produtoras de cana-de-açúcar no setor centro-sul do estado é algo bastante preocupante do ponto de vista da conservação dos solos e das águas subterrâneas, tendo em vista a característica drenante dos solos. As águas superficiais pertencentes à bacia hidrográfica do rio Paraná que drenam o setor centro-sul do estado deverão ser as mais atingidas pela fertirrigação, caso haja saturação do solo e contaminação dos fluxos d'água superficiais. Considerando a importância dessa bacia hidrográfica para o país, o aumento do nível de poluição em seus cursos fluviais torna-se altamente preocupante.

Portanto, o aumento da fertirrigação em decorrência da expansão da cultura da cana-de-açúcar pode levar a um alto risco de contaminação 
dos solos e águas superficiais e subterrâneas. Considerando que a vinhaça é produzida em grande quantidade e frequentemente utilizado na fertirrigação, altas dosagens desse efluente podem ser utilizadas na fertirrigação e causar danos severos e irreparáveis ao meio ambiente.

\section{Considerações finais}

O cenário descrito de alta vulnerabilidade natural das terras à contaminação por vinhaça coloca o estado de Goiás em situação de alta exposição ao risco de contaminação, tanto dos solos quanto dos corpos d'água superficiais e subterrâneos. Este fato, aliado a práticas agrícolas inadequadas, pode levar a uma situação de insustentabilidade ambiental.

Assim, a caracterização da vulnerabilidade à contaminação das terras do estado de Goiás, ainda que preliminar, permite orientar estudos que envolvam o uso e a ocupação das terras, servindo de base para propostas de ação de sustentabilidade dessas áreas mediante a realização de estudos específicos no que se refere à utilização da vinhaça na fertirrigação.

Por fim, convém ressaltar que um dos aspectos importantes para a realização desta pesquisa deveu-se à utilização do SIG (programa Spring), revelando o seu potencial em gerar informações a partir de um banco de dados, tornando-o um instrumento fundamental para ser utilizado em estudos de impactos ambientais.

Nota

1. Os mapas constantes das figuras 2, 3 e 4 foram gerados a partir da Base Cartográfica do Projeto Radambrasil - IBGE. Disponível em: http://www.sieg.go.gov.br/ produtos..

\section{Referências}

ALMEIDA, L. et al. Hidrogeologia do Estado de Goiás. Secretaria da Indústria e Comércio. Superintendência de Geologia e Mineração. Goiânia, 2006. (Série Geologia e Mineração, n. 1).

CAMBUIM, F. A. A ação da vinhaça sobre a retenção de umidade, ph, acidez total, acumulação e lixiviação de nutrientes em solo arenoso. Recife, 1983. 133p. Dissertação (Mestrado em Ciência do Solo) - Universidade Federal Rural de Pernambuco. 
CARVALHO, A. L. E.; PODESTÁ FILHO, J. A. Solos. In: DUARTE, A. C. (Ed.). Geografia do Brasil: região Centro-Oeste. Rio de Janeiro: IBGE, 1989. p. 91-105.

CASTRO, S. S. et al. Estudo da expansão da cana-de-açúcar no estado de Goiás: subsídios para uma avaliação do potencial de impactos ambientais. In: FORUM DE CIÊNCIA E TECNOLOGIA DO CERRADO, II, 2007. Semana de Ciência e Tecnologia. Goiânia: SBPC, 2007, p. 9-17.

DE CAMPOS, A. B. et al. Análise do comportamento espacial e temporal das temperaturas e pluviosidades no estado de Goiás. In: ALMEIDA, Maria Geralda de (Org.). Abordagens geográficas de Goiás: o natural e o social na contemporaneidade. Goiânia: Ed. da UFG, 2002. p. 91-118.

DEL'ARCO, J. O.; BEZERRA, P. E. L. Geologia. In: DUARTE, A. C. (Ed.). Geografia do Brasil: região Centro-Oeste. Rio de Janeiro: IBGE, 1989. p. 35-51.

GOMES, M. A. F. et al. Mapeamento expedito dos potenciais de infiltração e de escoamento superficial da água para os solos da microbacia do Córrego Espraiado em Ribeirão Preto-SP. In: CONGRESSO LATINO AMERICANO DE CIÊNCIA DO SOLO, 13., Águas de Lindóia, 1996. Anais... Águas de Lindóia: ESLAQ/SBCS, 1996b. 4 p. (Editado em CD ROM).

FREIRE, W. J.; CORTEZ, L. A. B. Vinhaça de cana-de-açúcar. Guaíba (RS): Agropecuária, 2000.

FOSTER, S. et al. Proteccion de la calidad del água subterrânea: guia para empresas de água, autoridades municipales y agencias ambientales. Madri: Mundi-Prensa Libros, 2003.

GOIÁS. Secretaria de Indústria e Comércio. Superintendência de Geologia e Mineração. Base cartográfica digital vetorial a partir da base cartográfica 1:250.000, IBGE. Curvas de Nível da Base Cartográfica Vetorial Digital ANA - revisão de topologia, alimentação, atualizações e edificação da carta SGM/SIC disponível em http://www.sieg.go.gov.br/produtos.

GOMES, M. A. F.; SPADOTTO, C. A.; PESSOA, M. C. Avaliação da vulnerabilidade natural dos solos em áreas agrícolas: subsídio à avaliação do risco de contaminação do lençol freático por agroquímicos. Revista Ecotoxicologia e Meio Ambiente, v. 12, p. 169-179, Curitiba, jan. 2002.

GOMES, M. A. et al. Caracterização das áreas de afloramento do aquífero Guarani no Brasil: base para uma proposta de gestão sustentável. Jaguariúna: Embrapa Meio Ambiente, 2006.

IEL - INSTITUTO EUVALDO LODI. O novo ciclo da cana: estudo sobre a competitividade do sistema agroindustrial da cana-de-açúcar e prospecção de novos investimentos. IEL/NC/SEBRAE,2006. Disponível em: http//www.iel.cni.org.br. Acesso em: 21 jul. 2007.

JORNAL DA CANA. Conheça o setor. Disponível em: http//www.jornalcana.com. br. Acesso em: 21 jul. 2007.

LYRA, M. R. C. C.; ROLIM, M. M.; SILVA, J. A. A. da. Topossequência de solos fertigados com vinhaça: contribuição para a qualidade das águas do lençol freático. 
Revista Brasileira de Engenharia Agrícola e Ambiental, v. 7, n. 3, p. 525-532, Campina Grande, PB, 2003.

LUDOVICE, M. T. Estudo do efeito poluente da vinhaça infiltrada em canal condutor de terra sobre o lençol freático. Campinas, 1996. 143p. 94p. Dissertação (Mestrado em Engenharia Civil) - Programa de Pós-Graduação em Engenharia Civil, Uiversidade Estadual de Campinas, Unicamp.

ROSSETTO, A. J. Utilização agronômica dos subprodutos e resíduos da indústria açucareira e alcooleira. In: PARANHOS, S. B. (Ed.). Cana-de-açúcar: cultivo e utilização. Campinas: Fundação Cargill, p. 435-504, 1987, v. 2.

SILVA, M. A. S. da; GRIEBELER, N. P.; BORGES, L. C. Uso de vinhaça e impactos nas propriedades do solo e lençol freático. Revista Brasileira de Engenharia Agrícola Ambiental, v. 11, n. 1, p. 108-114, Campina Grande, PB, 2007.

SILVA, M. A. S. da. Impactos da aplicação de vinhaça sobre as propriedades químicas do solo e de seu efluente. Goiânia, 2007. 94p. Tese (Doutorado em Agronomia, com Ênfase em Solo e Água) - Escola de Agronomia, Universidade Federal de Goiás.

Maria Gonçalves da Silva Barbalho - Assessora Especial da Secretaria de Estado da Fazenda de Goiás.

Alfredo Borges de Campos - Professor do Instituto de Estudos Sócio-Ambientais - Universidade Federal de Goiás. 